\title{
Effects of Social Skill Training Program on Social Skills of Young People
}

\author{
Ömer Gökel ${ }^{1 *}$, Gökmen Dağlı ${ }^{2}$ \\ ${ }^{1}$ Department of Psychological Counseling and Guidance, Near East University, N. CYPRUS \\ ${ }^{2}$ Ataturk Faculty of Education, Near East University, N. CYPRUS
}

Received 12 June 2017 • Revised 9 September 2017 • Accepted 6 October 2017

\begin{abstract}
This research was done in order to investigate the effects of the social skill training program on the social skill levels of young people in the age of military service in Cyprus. The sample of the investigation consists of 68 young people, who were applied to the military service in 2015. In order to determine social skill levels of the participants, Social Skill Inventory (SSI) was used. And the effects of the social skill training program on the social skill levels of participants were analyzed by the experimental method, which was based on pre-test and post-test model. As a result of the comparison, there were significant differences found between the pre-test scores of the test group before the execution of social skill training program and post-test scores after the execution of social skill training program. In the light of the data, it was concluded that the social skill training program has a positive impact on the social skill level of participants.
\end{abstract}

Keywords: military service, social skills, social skill incompetence, social learning model

\section{INTRODUCTION}

Mankind has an effort to be together, interact and communicate with other people from the creation of human beings to the present. The willingness of individuals to live together has made the social life inevitable. For this reason, communicating and maintaining the communication play a very important role within the community. Communication, which is effective in every period of life, starts to develop from childhood and continue to develop throughout education life. For maintaining and continuing this communication in a healthy way, people need some social skills and social competences.

Social skills can be grouped into 4 types of skills which are namely survival, interpersonal, problem solving and conflict resolution skills. Survival skills can be defined as the skills which include obeying rules and following directions. In addition, listening orders and suggestions are also included in these skills. Interpersonal skills on the other hand include skills such as empathy, learning collaboratively, sharing and relationships. Problem solving skills, differently, includes skills such as responsibility taking, help requesting, decision making and independence seeking. Finally, conflict resolution skills include skills such as coping with difficulties and apologising. These skills also include internal peace of the people where the conflict mostly occurs (Johnson, 2016).

In fact, improving social skills are rather important for personal and professional developments of the people since improving these skills help people to become better relationship builders. Improvements of these skills are mostly done with applying skill training practices. These trainings mostly utilise behavioural approach in order for improving people's communication, decision making, problem solving, self-management, self-control and competitive skills (IES, 2013). These trainings mostly performed in group surroundings. In addition, these trainings are mostly performed in clinics and not use classic classroom surroundings. Each and every training session only focuses on one and new skill. In this, skill modelling, role-play, feedback, guidance and assignment to make practices for new skill utilise by the instructors. These sessions also includes communication, participation of the group members and cooperation among them (Rudolph, 2005).

However, Gresham (2004) claimed that there is lack of literature on measuring the effect of social skills trainings on the social skills of the people. Therefore, this research was done in order to investigate the effects of the social 


\section{Contribution of this paper to the literature}

- With this social skill training program, fear of military service and the problem of the adoption to the military zone will be eliminated.

- For not having done any research on the subject in the past years, this research will be a new source and will contribute to new regulations in the military system and the social skills training program may be included in the military forces training system.

- This program can also be used for people who have problems such as communicating others and continuing communicating, shyness, self-expression, friendship, lack of self-confidence, and to trust anyone.

- There are not enough studies have been done to measure the effects of social skills training programs. It is thought that this work will provide the necessary contribution in this area.

skill training program on the social skill levels of young people between the 18-22 years of age. This age group of people particularly chosen due to the fact the people in Northern Cyprus mostly joins to military in this particular age frame.

Military service is such a different environment, having its own unique and disciplinary rules. It has its own rules within the organisation and it is accepted as a stress factor for almost each and every young person because of the need for an adaptation to this environment. Some young people do not have any problems adapting to the environment of the military service which is seen as a stressful lifestyle, however, some are having difficulties to adapt and face with various mental problems. A person who has a developed social skills are expected to adapt the military environment easily since it is believed that relationships between individuals as well as businesses related interactions occur based on the social skills that the people have.

It is thought that a young person, who has never left his/her family and his/her social environment in the course of his/her life, experiences significant changes in his perception, thinking and behaviour, generally in his/her adaptation processes after joining in the military service. This occurs due to the radical differences between civil lifestyles and military service. When a young person leaves his/her existing environment and encounters a new lifestyle and duties as specified by strict military service rules, he/she elicits different patterns of feelings and behaviours.

For this reason, military service may cause psychological issues in certain circumstances. In particular, taking individuals who are passing through the period of puberty and already suffering from some of the psychological and social challenges of this period, in the military service may partly determine various troubles in a military zone as some of their needs go unsatisfied in this new way of living. Solving these issues will have positive effects on the motivation and psychological moods of young people and it will help them to carry out their civil life as socially skilled individuals after their military service is completed.

\section{LITERATURE REVIEW}

Social relations are one of the significant parts of the human's life. A person spends an important part of his daily routine by communicating with others. The quality of these relations plays an important role both in the life of an individual and the life of a society.

One of the most important facts determining the development of quality social relations rises from the people's social skills. In other words, having a sufficient set of social skills helps people in building healthy social relations.

In general social skills are the way of behaviour exhibited in social situations (Hops, 1983). In other words, skills are the capacities to exhibit certain kinds of behaviour that are useful for both, individuals and other individuals in the community (Dowrick, 1986). People tend to interact and carry on interacting with family, friends and close social groups. Having sufficient social skills is necessary for efficient and fruitful interaction during this process. Individuals with a sufficient set of social skills exhibit a certain pattern of behaviour such as expressing themselves, understanding and caring for others, and thereby their behaviour is reinforced by the recognition of other's feedback and communication (Segrin, 2001).

In this perspective it can be said that social skills are socially informed appropriate behaviours that make communication with others possible, and above all, it indirectly indicates a certain set of behaviours that is not socially approved (Gresham and Eliot, 1990). They enable people to establish healthy and mutual relationships with the other people around them. They make people accepted in their social surroundings as higher social skills make people get a positive response from other people (Cartledge and Milburn, 1978).

According to Yigit (2008), not all individuals are qualified in exhibiting proper social skills, skills that are ultimately vital for interaction among individuals. Lack of sufficient social skills may cause negative results in the mutual interaction among individuals and adapts to the environment and, this, in turn, leads to incompetence in 
social skills. According to King (2000), incompetency in social skills is not to be able to exhibit the fundamental patterns of behaviour appropriate within the society, which actually originates from a lack of information necessary to perform social skills. In addition, a person who has a lack of social skills cannot display the appropriate behaviour when faced with problems.

Gresham (2004) claimed that there are six general conclusions that can be reached by examining the literature on social skills trainings. Among them, the first one is related to effectiveness of the social skills training programs. In this, Gresham (2004) stated that in order for these trainings to be successful, they have to combine coaching, modelling and reinforcement processes.

The second one is the weakness related to lack of cognitive-behavioural procedures. The third one is on the other hand related to the weakness of not having enough meta-analytic literature review on the social skills. In fact, Gresham (2004) claimed that literature on the subject do not reveal the consistent results about the effectiveness of social skills trainings on each and every situation and/or in one particular time frame. However, many studies found a modest effect on of the trainings on the social skills. The fourth conclusion which Gresham (2004) state is related to lack of measurement tools related to effectiveness. In this perspective, Gresham (2004) claimed that measurement related to cognitive-behavioural interventions has lack of social validity. The fifth conclusion was related to existence of the relationship with social skills trainings and effect of intervention. The final conclusion is on the other hand related to the fact that trainings can improve the skills needed.

Social skills are learned behaviors therefore training and teaching strategies are extremely important in the social skill training. Purpose of the social skills training is to improve the interaction skills of individuals, facilitate their adaptation to the environment where they live and increase the quality of life. There are 2 main teaching theories in social skill training. These are the developmental theories and social learning or cognitive social learning theory (Cubukcu and Gultekin, 2006).

Teaching is examined according to physical and mental development of human in developmental theories (Elksnin \& Elksnin, 1998), however teaching is managed on some concepts such as imitation, modeling and observation in cognitive social learning theory (Ladd \& Mize, 1983; Johnson, 2006). Although, it is seen that the social learning theory has begun to be used in areas such as mathematics (Mahmud, 2017), the cognitive-social learning theory is mostly used in social skills training (Özabac1, 2006). In this context social learning theory is also based on this study.

According to social learning theory, behavior is the result of a continuous interaction between personal and environmental conditions. Environmental conditions are shaping the behavior through learning, whereas the behavior of the individual also shapes the environment. Social learning theory has emphasized that the individual is not passive in the face of environmental conditioning; on the contrary, the individual is someone who is making plans, making comparisons, making comments and evaluations (Can, 2000).

Individual observes the behaviors of others and then behaves in a similar way in similar conditions in the social learning model. Thus, many social behaviors are learned with this model. In the social learning theory developed by Albert Bandura, learning takes place by modeling or observation (Ladd \& Mize, 1983). According to Ladd and Mize (1983) who studied the social training program based on the social learning approach there must be 3 basic process in the social skill training program: instruction, rehearsal and feedback.

Instruction can be done both verbally and modeling. In verbal instruction, social skills are defined and explained how to do it verbally. In modeling, social skills are introduced by symbolic or living models and showed how it should be done. Rehearsing is a very important process in improving one's social skill performance and ensuring the permanence of skills. To think about the social skills and related steps, envisioning or apply personally are the process of the rehearsal. Feedback is ensuring the correct implementation of shown social skills and it is very important to ensure the continuity of social skills (Ladd \& Mize, 1983).

From these conclusions it can be understood that lacking a sufficient set of social skills or an inability to learn it, may cause failures in adaptation to the environment and building relationships with other individuals. This fact is not any different when it comes to military life. Personal characteristics of young people and living in a new environment with the operative psychological and social issues in the background can also lead to incompetence in social skills when their needs are unsatisfied.

Having a sufficient set of social skills helps building healthy social relations with others. The early ages of life are one of the most important factors in gaining social skills, and it is also crucial for gaining various other kinds of skills. Having a sufficient set of social skills in the early ages brings forth certain decisive advantages to the individual in his later life, enabling him/her to become more successful than others at certain subjects and fields. Military joining age can also be considered as the age (18-22) when people still develop their social skills.

For this reason, this work focuses on determining the social skill competence of young people before entering the military service and to raise the level of social skills with a pre-prepared training program and to eliminate some deficiencies. By determining the deficiencies it is aimed to provide some solutions. 
Only through solving these issues, one can expect that young people will be able to gain self-confidence and become more functional individuals in their military life, as well as becoming psychologically and physiologically mature. As a result, it has been expected them to become individuals that build excellent social relations.

\section{RESEARCH METHODOLOGY}

\section{Research Subject and Sampling Data}

In this research, the experimental method, which was based on pre-test and post-test model was used. The ultimate objective of this study is to investigate the effects of the social skill training program on the social skill levels of young people between the 18-22 years of age. This age group of people particularly chosen due to the fact the people in Northern Cyprus mostly joins to military in this particular age frame.

Therefore, people who applied to military service in 2015 in Northern Cyprus forms the population of this study. In 2015, a total of 1255 people applied to military service in the country. Based on this fact, sample size calculation is carried out. In this manner, sample size calculator was used in this study. This calculator can be reached from the following link: https://www.surveysystem.com/sscalc.htm. In the calculation, confidence level was taken as $95 \%$ and confidence interval (error estimation) was set as $10 \%$. Setting high level of error estimation and setting low level of confidence was related to difficulty of reaching the particular characteristic of this study required. Accordingly, a total of 89 respondents were determined as a sample size.

The research was carried out in front of the military service registration base in Nicosia, Northern Cyprus. All questionnaires were distributed nevertheless, only 68 questionnaires were included in the analysis since 21 questionnaires were not filled properly.

Questionnaire was prepared based on the Social Skills Inventory (SSI). Developed first by Riggio (1986) and then evolved into its recent form after the revision in 1989, is a type of self-identifying scale which can be applied to individuals over the age of 14 and consists of 90 items/articles and six subscales. SSI computes the sum of the general social skill level, which covers all social competence or social skills. The subscales of SSI are defined as 1Emotional Expressivity (EE), 2- Emotional Sensitivity (ES) 3- Emotional Control (EC), 4- Social Expressivity (SE), 5Social Sensitivity (SS), 6- Social Control (SC). Each subscale consists of 15 items. A 5 point Likert type answer sheet was prepared for the items in the inventory. The highest mark on the answer sheet is " 5 ", the lowest is " 1 ".

One can only get a minimum of 90 points and a maximum of 450 from the whole inventory. In determining the reliability of the scale, cronbach Alpha analysis was used. The result showed that the scale is highly reliable as the measurement indicated a .94 reliability (cronbach Alpha).

In order to measure the social skills of the participants, Social Skill Training Program was created. Social skill training program was prepared according to previous studies of the researcher and findings, which obtained from the researches about the social skills. According to the findings of the previous researches, a social skill training program was developed by the researcher for eight sessions about adapting to military service lifestyle as a priority, communicating, understanding others, taking initiative and being responsible. The purpose and the process of the social skills training program were informed to the participants by the researcher before the application of the program. After the first measurement of the SSI scores, the social skill training program was applied to the test group for 2 hours 1 times a week for 8 weeks and nothing applied to the control group. After the social skill training period, the participants joined in the military training centre for four weeks. And at the end of this period post-test was applied to the test and control group.

\section{Data Analysis}

\section{Participants}

The participants of the investigation consist of 68 young people, who were applied to the military service in 2015 in North Cyprus.

The participants who had taken 90-210 points from the SSI are included in the experiment group and who had taken 211-330 points are included in the control group. The distribution of experimental and control groups according to the education level is shown in Table 1. The age of participants ranged from 18 to $22(\mathrm{M}=19.8$; $\mathrm{SD}=0.844)$. According to the education level; $2.9 \%(\mathrm{n}=2)$ of the participants are illiterate; $48.5 \%(\mathrm{n}=33)$ of the participants are primary school graduates; $22 \%(n=15)$ of the participants are secondary school graduates; $16.2 \%$ $(n=11)$ of the participants are high school graduates and $10.3 \%(n=7)$ of the participants are university graduates. 
Table 1. The Distribution of Experiment and Control Groups

\begin{tabular}{|c|c|c|c|c|c|c|c|}
\hline Group & Education Level & $\mathbf{n}$ & $\%$ & Group & Education Level & $\mathbf{n}$ & $\%$ \\
\hline \multirow{5}{*}{ Experiment } & Illiterate & 2 & $5,9 \%$ & \multirow{5}{*}{ Control } & Illiterate & 0 & $0,0 \%$ \\
\hline & Primary & 21 & $61,8 \%$ & & Primary & 12 & $35,3 \%$ \\
\hline & Secondary & 6 & $17,6 \%$ & & Secondary & 9 & $26,5 \%$ \\
\hline & High School & 3 & $8,8 \%$ & & High School & 8 & $23,5 \%$ \\
\hline & University & 2 & $5,9 \%$ & & University & 5 & $14,7 \%$ \\
\hline \multicolumn{2}{|c|}{ Total } & 34 & $100,0 \%$ & & Total & 34 & $100,0 \%$ \\
\hline
\end{tabular}

Table 2. Pre-test Results of the Participants in the Experimental and Control Groups

\begin{tabular}{ccccc}
\hline Groups & $\mathbf{n}$ & $\mathbf{M}$ & $\mathbf{S D}$ & $\mathbf{t}$ \\
\hline Experiment & 34 & 195,32 & 13,07 & \multirow{2}{*}{4,27} \\
\hline Control & 34 & 295,67 & 11,15 & 0,00 \\
\hline
\end{tabular}

In the light of the data obtained from Table 2; there was significant difference found between pre-test mean scores of the experimental group $(\mathrm{M}=195.32)$ and pre-test mean scores of control groups $(\mathrm{M}=295.67)$ and it was found that there was balanced distribution between the groups $(p<.05)$.

The main problems of the pre-test results which found in low and middle level; (i) adaptation to military service lifestyle, (ii) move away from the family and social environment, (iii) restriction of freedom, (iv) being under command, (v) not being ready for taking responsibility, and (vi) being shy. As for the solution of these problem areas, social skill training program is developed based on the social learning and rational-emotive behavioural therapy (REBT). This theory used in the step of preparing program based due to the fact that social skill is a behaviour acquired through learning and it is a learned individual behaviour that effect person to avoid enter the social environment due to the both personality traits (shy, introverted, weak self-confidence, etc.) and irrational beliefs. According to Ellis (2004), the belief system is divided into rational and non-rational form in the rational emotive behavioural approach.

Emotionally healthy people have a rational belief, however emotionally disturbed people have a non-rational belief (it would be bad If I do not love by others, If I want to see myself worthy I have to be very successful and excellent, I shouldn't do wrong, I have to dissemble my feelings, unhappiness cannot be controlled because it caused from the external factors, I'm a loser, I cannot stand criticism, I'm an unsuccessful person, bad and malevolent persons must be punished, and so on). In the context of this research, the social skill training program is developed to gain awareness against irrational beliefs, to get rid of irrational beliefs, and it is intended to raise the level of social skills. Along with this program, the following abilities and skills targeted to perform both in the military service and in the social life after the demobilisation mainly: to get rid of unwanted behaviour, to gain the ability to ensure desired behaviour, to perform the changes in feelings, thoughts, and behaviour. At the end of the program, it is also aimed to have the skills and behaviours listed below:

- Be able to realise an irrational belief and focusing on rational belief,

- Be able to communicate with people and continue,

- To realise liked or disliked emotions, ideas and messages when communicating with people and to express them verbal or nonverbal,

- Being self-confident and to control him/herself,

- To make empathy,

- To get rid of shyness and to be sociable,

- To be responsible.

The titles of the 8 session social skill training program and the utilised program resources when developing this program are listed below:

I. Session (Meeting, mingling, caring): utilised program resources: A group social skills training program with psychiatric patients: outcome, drop-out rate and prediction (Van Dam-Baggen \& Kraaimat, 1985); Social skills training with children and young people: theory, evidence and practice (Spence, 2003); Social skills problems in neurotic outpatients: social skills training with and without cognitive modification (Stravynski, Marks \& Yule, 1994).

II. Session (Character analysis, differences, interests and values): utilised program resources; examples of group counseling programs (Kulaksızoğlu, 2004); 101 ways to teach children social skills (Shapiro, 2004); building social skills through activities (Pettry, 2006). 
Table 3. Pre-Test and Post-Test Scores of the Participants in the Experimental Group

\begin{tabular}{cccccc}
\hline Measurement & $\mathbf{n}$ & $\mathbf{M}$ & $\mathbf{S D}$ & $\mathbf{t}$ & $\mathbf{P}$ \\
\hline Pre-test & 34 & 195,32 & 13,07 & \multirow{2}{*}{2,98} & \multirow{2}{*}{0,00} \\
\hline Post-test & 34 & 302,38 & 27,23 & \\
\hline
\end{tabular}

Table 4. Pre-Test and Post-Test Scores of the Participants in the Control Group

\begin{tabular}{cccccc}
\hline Measurement & $\mathbf{n}$ & $\mathbf{M}$ & $\mathbf{S D}$ & $\mathbf{t}$ & $\mathbf{P}$ \\
\hline Pre-test & 34 & 295,67 & 11,15 & \multirow{2}{*}{1,31} & 0,198 \\
\hline Post-test & 34 & 296,61 & 9,39 & & \\
\hline
\end{tabular}

Table 5. Post-Test Scores of the Experimental and Control Group

\begin{tabular}{cccccc}
\hline Groups & $\mathbf{n}$ & $\mathbf{M}$ & SD & t & P \\
\hline Experiment & 34 & 302,38 & 27,23 & \multirow{2}{*}{6,47} & \multirow{2}{*}{0,00} \\
\hline Control & 34 & 296,61 & 9,39 & &
\end{tabular}

III. Session (Communicating and understanding others): utilised program resources; Improving adolescent social competence peer interactions using correspondence training (Ralp et all, 1998); Effects of social skills training on adolescents interpersonal level (Uzamaz, 2000); Effect of training program based on human relations skills on the social skills level of group members (Kalkan \& Sardoğan, 2003); 101 ways to improve your communication skills (Condrill \& Bough, 2005).

IV.Session (Unity and solidarity, creating an environment of confidence): utilised program resources; Examples of group counseling programs (Kulaksızoğlu, 2004); 101 ways to teach children social skills (Shapiro, 2004); Building social skills through activities (Pettry, 2006).

V. Session (Get rid of the irrational belief): utilised program resource; Why I (really) became a therapist (Ellis, 2004).

VI. Session (Taking initiative): utilised program resources; A cognitive-behavioral approach to social skills training with shy persons (Haynes-Clements \& Avery, 1984); Evaluating a social skills training program for hong kong students (Chung \& Watkins, 1995); Effects of social skills training on the shyness levels of high school second grade students (Yildirım, 2006).

VII. Session (Developing the sense of responsibility): utilised program resources: Social skills training for young adolescents (Wise et all, 1991); Teaching respect and responsibility in inclusive classrooms (Warger \& Rutherford, 1997); Character education (Burch, 2003); character matters (Lickona, 2004).

VIII. Session (Summarising and Ending): The topics and learning material, which were covered within those two months was summarized. Each participant was encouraged to share his experience and learns during training with the group. They left each other hoping to meet again in the army, and the session will be finished.

\section{Results}

Pre-test and post-test scores of the participants in the experimental group are shown in Table 3. According to Table 3, it was found that the pre-test scores of the experimental group were $M=195.32$ and the post-test scores found $\mathrm{M}=302.38$. There was an increase of 107 points between pre-test and post-test scores. According to these results, there were significant differences found between the average $(p<.05)$. These findings showed that the social skill program implemented to the participants in the experimental group was successful and it helped to increase the social skill levels of the participants. Before the implementation of social skill program, SSI scores were low level (90-210) and after the implementation of social skills program SSI scores were increased to the mid-level (211330).

Pre-test and post-test scores of the participants in the control group are shown in Table 4. According to data obtained from Table 4, there was 0.94 points difference found between the pre-test scores $(\mathrm{M}=295.67)$ and post-test scores $(M=296.61)$ of the control groups. Although there was an increase of 0.94 points between the pre-test and post-test scores, the difference between the average was not found significant ( $p>.05)$.

The results are given in Table 5 if there were any differences between the post-test scores of experimental and control group. According to the Table 5, the post-test scores of the participants in the experimental group are found $\mathrm{M}=302.38$ and the post-test score in control groups is calculated $\mathrm{M}=296.61$. There was an increase of 5.77 points between the post-test scores of the experimental group and post-test scores of the control group and the difference between the average was found significant $(\mathrm{p}<.05)$. According to these results, it is seen that there was a significant impact in increasing the social skill levels of the participants after implementing the social skill training program. 


\section{DISCUSSION AND CONCLUSION}

As a conclusion, it was found that social skill training program was successful to the extent that it helps to raise the social skill level of participants with low scores to higher scores.

The average of pre-test scores of participants in the test group before the execution of the social skill training program was low level and the average of test scores of participants after the execution of the program was increased to mid-level. According to these results, there was a significant difference between the average scores. Hence it was concluded the social skill training program has a significant impact on the rise of social skill levels of participants. However, the comparison of the average of pre-test scores of the participants in the control group and the average of post-test scores of the participants, it was found that there was no significant difference found. Although there was a rise of 0.94 points, it indicates that the difference between the means was not statistically significant.

When the studies related to social skills training were analyzed, there were some works found similar with these results. Torun (2008) studied the effects of the social skill training program on the social skill level of soldiers. He found that the social skill level of soldier in the experiment group was higher than the control group and there were significant differences between the pre-test and post-test scores. Bulkeley and Cramer (1990) studied the effects of the social skill training program on the young adolescents who lack social skills and they found that the students in the experimental group had an increase in social skills scores. In another work, Yuksel (1997) studied the effects of social skill training program on the social skill levels of university students and he found that the social skill level of the students in the experimental group were higher than the control group.

Uzamaz (2000) examined the effects of social skills training on adolescents interpersonal level and he found that the social skills training increased the level of interpersonal relationships of adolescents. Lastly, Newbery and Lindsay (2003) studied the effect of social skills training on the locus of control of youth from residential care and they found that the internal locus of control of students participating in social skills training was higher than the control group. These findings show that the social skill training programs helps participants to raise their social skill level and to overcome their weakness and incompetence.

It is thought that the other factors that lead young people to have poor scores in social skill tests, the following can be listed: irresponsibility in their civil life, adaptation, solitude, being unable to get away from solitude due to the personality disorders or negative aspects of living alone, chronic feeling of emptiness spreading over their minds as it becomes difficult to maintain the social bond and communication with their family, friends, girlfriends, etc., before joining the military service, absence of family and friends supporting them in bad times, financial, and spiritual problems.

It is seen that the young people in the age of military have actually adaptation problems. In a study related to the adaptation problems in the military service, Kurt (2003) found that the some reasons causes the adaptation issues: civil lifestyle and military lifestyle are dramatically different to the extent that a young person, who for the first time in his life, leaves his civil life behind him, his most intimate friends, family and social environment, finds nothing comforting in military life at all. In other words, his comfort zone is being terminated once he joins the military service. In another work, Demirturk (2005) found that the military service would give a long break from the social life and it would cause the 'jobs-to-be-done' to pile up during service. As an example of unfinished tasks and interruption to one's social life, one can mention for instance: being married or engaged, expecting a new baby in the family, leaving school, losing a job or losing job opportunities, and not being with their close relatives in the case of health issues or death of beloved ones.

It is vitally important for the military service to take into account that with young people who have low social skills, the combat power will drop dramatically, so there should be some security measures/precautions in order to deal with this issue. Social skills are generally thought to be skills that are necessary for the individual to build a healthy and mutually interaction with other people. So staff members with poor social skills could cause a lot of trouble in the army, and these problems cannot be ignored. In this context, having sufficient social skills has seen as an important element in developing healthy relationships, complying with the principles and norms of social life, being responsible, helping people, and ability to use the acquisitions. Thus, the person becomes aware that the members of the community in which he lived and to fulfil its responsibilities on the social aspect, it is possible to acquire the social skills they will need throughout life.

As a suggestion, implementation of this program before entering the military service is a great importance. In this way, social skill problem of the young people will be determined and it will be overcome by the program. However, problems may occur again during the military service period. So, it should be given sufficient social support to the people who lack social skill and ensuring the appropriate health services, increasing their socialisation and enabling them to use their personal skills to make the social and cultural activities. Also, helping the people to participate in social activities in young ages, developing the skills, performing works that will let 
them to be creative and productive in their social life and establishment of occupation areas should be ensured to use their free time effectively and efficiently.

\section{REFERENCES}

Branstain, M. R., Bellack, A. S., \& Herson, M. (1977). Social skills training for unassertive children: A multiple baseline analysis, Journal of Applied Behavior Analysis, 10, 183-195. doi:10.1901/jaba.1977.10-183

Bulkeley, R., \& Cramer, D. (1990). Social skills training with young adolescents. Journal of Youth and Adolescence. 19 (5), 451-463. doi:10.1007/BF01537474

Burch, R. B. (2003). Character education: resource guide. California: Creative Teaching Press.

Cartledge, G., \& Milburn, J. F. (1978). The case for teaching social skills in the classroom: A review. Review of Educational Research, 48, 133-156. doi:10.3102/00346543048001133

Chung, C. H., \& Watkins, D. (1995). Evaluating a social skills training program for Hong Kong students, Journal of Social Psychology, 135(4), 527-528. doi:10.1080/ 00224545.1995.9712222

Combs, M. L., \& Slaby, D. A. (1977). Social skills training with children. Advances in Clinical Child Psychology, 1, 161201. doi:10.1007/978-1-4613-9799-1_5

Condrill, J., \& Bough, B. (2005). 101 ways to improve your communication skills. California: GoalMinds, Inc.

Cubukcu, Z., \& Gultekin, M. (2006). Social skills required to be acquired in primary school. Turkish World Social Science Journal, 37, 155-174.

Demirturk, F. M. (2005). The impact of military training on the optimization of 'tolerance level' of privates and rankers (Master Thesis). Samsun: Ondokuz Mayis University.

Dowrick, P. W. (1986). Video training. Chapter 11 in social survival for children: A trainer's resource, New York: Brunner/Mazel.

Elksnin, L. K., \& Elksnin, N. (1998). Teaching social skills to students with learning and behavior problems. Intervention in School \& Clinic, 33(3), 131-141. doi:10.1177/105345129803300301

Ellis, A. (2004). Why I (really) became a therapist. Journal of Rational-Emotive and Cognitive-Behavior Therapy, 22, 7377. doi:10.1002/jclp.20166

Gresham, F. M., \& Elliott, S. N. (1990), Social skills rating system. MN: Circle Pines, AGS.

Gresham, F. M., Cook, C. R., Crews, S., \& Kern, L. (2004). Social skills training for children and youth with emotional and behavioral disorders: Validity considerations and future directions. Behavioral Disorders, 30(1), 32-46.

Haynes-Clements, L. A., \& Avery A.W. (1984). A cognitive-behavioral approach to social skills training with shy persons. Journal of Clinical Psychology, 40(3), 710-713. doi:10.1002/1097-4679

Hops, H. (1983). Children's social competence and skills: Current research practices and future directions. Behavior Therapy, 14, 3-18. doi:10.1016/S0005- 7894(83)80084-7

IES. (2013). What Works Clearinghouse. Retrieved from https://ies.ed.gov/ncee/wwc/EvidenceSnapshot/578

Johnson, G. (2006). Internet use and cognitive development: a theoretical framework. E-Learning, 3(4). doi:10.2304/elea.2006.3.4.565

Johnson, J. L. (2016). School-Wide Social Skills Instruction. Retrieved from https://vkc.mc.vanderbilt.edu/assets/files/resources/psisocialskills.pdf

Kalkan, M., \& Sardoğan, M. E. (2003). Effect of training program based on human relations skills on the social skills level of group members. 3P Journal, 11(2), 137-142.

King, R. (2000). Classroom-based social skills training as primary prevention in kindergarten: Teacher ratings of social functioning (Ph. D. Thesis). US: University of Missouri.

Kulaksızoglu, A. (2004). Examples of group counseling programs. Ankara: Nobel Publications.

Kurt, U. Y. (2003). The adaptation of rankers and privates, who completed their basic training and began performing their roles in a master troop unit, to military environment and military occupation (Master Thesis). Erzurum: Ataturk University.

Ladd, G. W., \& Mize, J. (1983). A cognitive-social learning model of social-skill training. Psychological Review, 90(2), 127-157. doi:10.1037/0033-295X.90.2.127

Lickona, T. (2004). Character matters. New York: Simon \& Schuster, Inc.

Mahmud, R. (2017). The development of social learning model based on metacognitive strategies to foster mathematics self-efficacy of senior high school students 9 Makassar, Indonesia. EURASIA Journal of Mathematics Science and Technology, 13(8), 4873-4883. doi:10.12973/eurasia.2017.00970a 
McFall, R. M. (1982). A review and reformulation of the concept of social skills. Behavioral Assessment, 4, 1-33. doi:10.1007/BF01321377

Newbery, E. H., \& Lindsay, J. F. (2003). The impact of social skills training and challenge course training on locus of control of youth from residential care. The Journal of Experiential Education, 23(1), 39-42. doi:10.1177/105382590002300107

Özabacı, N. (2006). Investigation of the relationship between children's social skills and their parents' social skills. Firat University Social Science Journal, 16(1), 163-179.

Pettry, D. W. (2006). Building social skills through activities. Retrieved from www.dannypettry.com/ebook_social_skills.pdf

Ralph, A., Hogan, S., Hill, M., Perkins, E., Ryan, J., \& Strong, L. (1998). Improving adolescent social competence in peer interactions using correspondence training. Education and Treatment of Children, 21(2), 171-194. Retrieved from http://www.jstor.org/stable/42899528.

Riggio, R. E. (1986). Assessment of basic social skills. Journal of Personality and Social Psychology, 51, 649-660. doi:10.1037/0022-3514.51.3.649

Rudolph, T. C. (2005) The effects of a social skills training program on children with ADHD: Generalization to the school setting (Graduate Thesis and Dissertations). Retrieved from http://scholarcommons.usf.edu/cgi/viewcontent.cgi?article=1837\&context=etd

Segrin, C. (2001). Social skills and negative life events: Testing the deficit stress generation hypothesis. Current Psychology, 20(1), 17-19. doi:10.1007/s12144-001- 1001-8

Shapiro, L. E. (2004). 101 ways to teach children social skills. USA: The Bureau for At-Risk Youth Publications.

Spence, S. H. (2003). Social skills training with children and young people: theory, evidence and practice. Child and Adolescent Mental Health, 8(2), 84-96. doi:10.1111/1475-3588.00051

Stravynski, A., Marks, I., \& Yule, W. (1982). Social skills problems in neurotic outpatients: social skills training with and without cognitive modification. Arch Gen Psychiatry, 39, 1378-1385. doi:10.1001/archpsyc.1982.04290120014003

Torun, M. (2008). Effects of the social skill training program on the social skill level of soldiers (Master Thesis). Ankara: Gazi University.

Uzamaz, F. (2000). Effects of social skills training on adolescents interpersonal level (Unpublished Master Thesis). Adana: Çukurova University.

Van Dam-Baggen, R., \& Kraaimat, F. (1985). A group social skills training program with psychiatric patients: outcome, drop-out rate and prediction. Behavioral Research and Theraphy, 24(2), 161-169. doi:10.1016/00057967(86)90087-2

Warger, C. L., \& Rutherford, R. B. (1997). Teaching respect and responsibility in inclusive classrooms: an instructional approach. Reclaiming Children and Youth, 6(3), 171-175.

Westwood, P. (1993). Commonsense methods for children with special needs strategies for the regular classroom. London: Routledge.

Wise, K. L., Bundy, E. A., Bundy, K. A., \& Wise, L. A. (1991). Social skills training for young adolescents. Adolescence, 26(101), 233-241.

Yigit, R. (2008). The comparatively analyzing of self-esteem, depression and social skills levels of elementary 2. level students in terms of some variables (Ph.D. Thesis). Konya: Selcuk University.

Yıldırım, M. (2006). Effects of social skills training on the shyness levels of high school second grade students (Unpublished Master Thesis). Ankara: Gazi University.

Yüksel, G. (1997). The effect of social skills training on the social skills level of university students (Unpublished Ph.D.Thesis). Ankara: Gazi University.

\section{http://www.ejmste.com}

